\title{
Fabrication of multifunctional carbon encapsulated Ni@NiO nanocomposites for oxygen reduction, oxygen evolution and lithium-ion battery anode materials
}

\author{
Dongyang $\mathrm{Xu}^{1}$, Congpu $\mathrm{Mu}^{2 *}$, Bochong Wang ${ }^{2}$, Jianyong Xiang ${ }^{1}$, Wenjun Ruan ${ }^{1}$, Fusheng Wen ${ }^{1 *}$, \\ Xia $\mathrm{Du}^{1}$, Zhongyuan $\mathrm{Liu}^{1 *}$ and Yongjun Tian ${ }^{1}$
}

\begin{abstract}
Multifunctional carbon encapsulated Ni@NiO nanocomposites (Ni@NiO@C) were synthesized for applications in oxygen reduction reactions (ORR), oxygen evolution reactions (OER) and lithium-ion batteries (LIB). The morphology was investigated via SEM and TEM, suggesting that the Ni@NiO@C nanocomposites have uniform and spherical core-shell structures. When the Ni@NiO@C nanocomposite is used as the catalyst in ORR, $\mathbf{9 0 \%}$ of the initial current density can be maintained after $15 \mathrm{~h}$ in $\mathrm{O}_{2}$-saturated $0.1 \mathrm{~mol} \mathrm{~L}^{-1} \mathrm{KOH}$ at $0.3 \mathrm{~V}$ under a rotation speed of $1600 \mathrm{rpm}$. As a catalyst for OER, the highest activity overpotential of the Ni@NiO@C nanocomposite electrocatalyst is $380 \mathrm{mV}$ (vs. RHE) under the current density of $10 \mathrm{~mA} \mathrm{~cm}$, and the Tafel slope was calculated to be $55 \mathrm{mV} \mathrm{dec}{ }^{-1}$ by linear fitting. Electrochemical performances of the $\mathrm{Ni@NiO@C} \mathrm{nanocomposites} \mathrm{used} \mathrm{as} \mathrm{LIB}$ electrodes exhibited a long cycling life with a high capacity of $750 \mathrm{~mA} \mathrm{~h} \mathrm{~g}^{-1}$ after 400 cycles under $200 \mathrm{~mA} \mathrm{~g}^{-1}$.
\end{abstract}

Keywords: oxygen evolution reaction, lithium-ion battery, oxygen reduction reaction, $\mathrm{NiO}$

\section{INTRODUCTION}

With the development of science and technology in society, the energy crisis and environmental pollution are becoming increasingly acute [1]. The energy crisis will affect the human lifestyle deeply by affecting energy access, consumption, and storage [2]. Therefore, the replacement of expensive and rare metal catalysts is a critical issue in industrial and academic fields. To minimize the effects, widespread investigations have been performed, taking both experimental and theoretical viewpoints [3]. The oxygen reduction reaction (ORR), with favorable activity and stability, was one of the key factors for the development of renewable energy in fuel cells and batteries $[4,5]$. One possible way to obtain clean energy is to produce hydrogen from water splitting. In this procedure, oxygen evolution reaction (OER) performance with low overpotential and high current densities is very important for large-scale production [6]. Considering energy storage [7], the lithium-ion battery (LIB) has been extensively studied because of its excellent properties, including large capacity and long-life cycling. The development of LIB anode materials with high capacities and super-long cyclic stability is one of the most important tasks [8]. Lately, nanocomposites based on various carbon materials [9] are being widely studied by researchers to resolve energy and environmental problems $[10,11]$. Carbon nanotubes, nanospheres, graphene nanocomposites, and so on have been studied as ORR electrocatalysts, OER electrocatalysts, and LIB anodes with excellent performances [12-14]. It would be a great challenge as well as huge progress for practical applications to combine these advantages in one carbon-based nanocomposite [15].

To achieve this, a possible solution is decorating the surface of the carbon substrate with metal and metal oxides [16]. Because of advantages such as high OER catalytic activity [17], high capacity as LIB anodes [18], and high activity and stability as ORR electrocatalysts, nickel and nickel oxides have been widely investigated as candidates for decorating carbon substrates [4]. As we know, improving the stability of ORR, enhancing the

\footnotetext{
${ }^{1}$ State Key Laboratory of Metastable Materials Science and Technology, Yanshan University, Qinhuangdao 066004, China

${ }^{2}$ Hebei Key Laboratory of Microstructure Material Physics, Yanshan University, Qinhuangdao 066004, China

Corresponding authors (emails: congpumu@ysu.edu.cn (Mu C); wenfsh03@126.com (Wen F); liuzy0319@yahoo.com (Liu Z))
} 


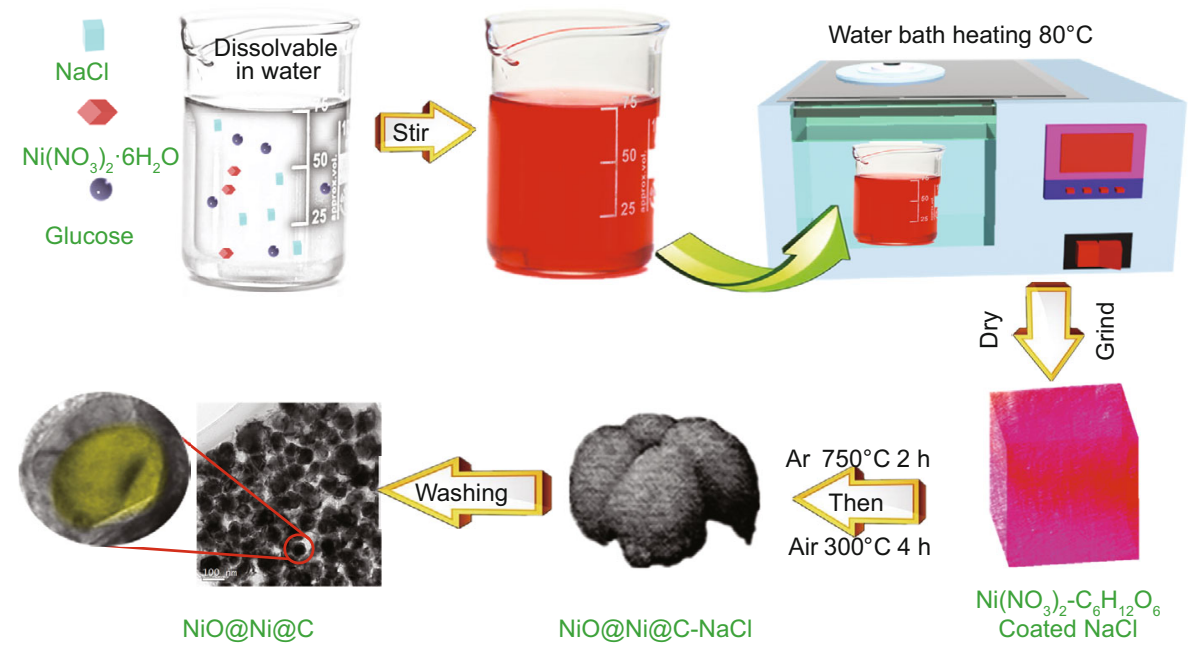

Figure 1 Schematic illustration of the formation of $\mathrm{Ni@NiO@C} \mathrm{nanocomposites.}$

conduction of OER, and reducing the pulverization effect in LIB are the keys to improve the electrochemical performances of nanocomposites, which can be severely restricted by the architectures of the different components of the nanocomposites [19]. Therefore, it is important to further investigate composites of nickel and nickel oxides and carbon materials for multifunctional applications.

In this paper, multifunctional carbon-encapsulated $\mathrm{Ni@NiO} \mathrm{nanocomposites} \mathrm{(Ni@NiO@C)} \mathrm{were} \mathrm{synthesized}$ and investigated systematically. Improvements in stability during ORR, enhancements in conduction in OER, and reduction of the pulverization effect in LIB were achieved, leading to excellent $\mathrm{Ni@NiO@C} \mathrm{performances} \mathrm{in} \mathrm{ORR,}$ OER, and LIB.

\section{EXPERIMENTAL SECTION}

A precursor solution was prepared by dissolving $\mathrm{Ni}$ $\left(\mathrm{NO}_{3}\right)_{2} \cdot 6 \mathrm{H}_{2} \mathrm{O}$, glucose, and sodium chloride in deionized water with stirring for $10 \mathrm{~min}$. The precursor solution was stirred and boiled in a hot water bath at $80^{\circ} \mathrm{C}$. Then, the intermediate product $\mathrm{Ni}\left(\mathrm{NO}_{3}\right)_{2}-\mathrm{C}_{6} \mathrm{H}_{12} \mathrm{O}_{6}$ coated with $\mathrm{NaCl}$ was calcined at $750^{\circ} \mathrm{C}$ for $2 \mathrm{~h}$ under an argon atmosphere $\left(50 \mathrm{~mL} \mathrm{~min}^{-1}\right)$ and then annealed at $300^{\circ} \mathrm{C}$ for $4 \mathrm{~h}$ in air. After cooling to room temperature, the obtained powder was washed with deionized water to dissolve the sodium chloride. Finally, the Ni@NiO@C nanocomposites were synthesized (as shown in Fig. 1).

The morphology and nanostructure of Ni@NiO@C nanocomposites were characterized by scanning electron microscopy (SEM, S-4800 Hitachi, Japan) and transmission electron microscopy (TEM, JEM-2010 JEOL, Japan). The crystal structure of the nanocomposite was measured using a Rigaku SmartLab X-ray diffractometer with $\mathrm{Cu}$ Ka radiation $(\lambda=1.5406 \AA)$. The Raman spectra were characterized at room temperature by a Renishaw inVia micro Raman spectroscope with a laser radiation of $514 \mathrm{~nm}$. The surface area and porous structure were determined by nitrogen adsorption at $77 \mathrm{~K}$ with a Quantachrome Autosorb, and the pore size distributions were obtained from nitrogen adsorption isotherms.

The Ni@NiO@C nanocomposites (50 mg) were dispersed in $10 \mathrm{~mL}$ mixed liquid of nafion $(100 \mu \mathrm{L}, 5 \mathrm{wt} . \%)$, ethanol and distilled water $(1: 4 \mathrm{v} / \mathrm{v})$, and sonicated for about $10 \mathrm{~min}$ to obtain a homogeneous solution. Then, $10 \mu \mathrm{L}$ of the solution was drawn out and loaded onto a glassy carbon rotating-disk electrode (RRDE-3A RRDE, ALS Co., Ltd., Japan), which has a standard three-electrode cell including platinum mesh as the auxiliary electrode. Linear scan voltammetry (LSV) and chronoamperometric response measurements were performed on rotating-disk electrode (RDE) in a $1 \mathrm{~mol} \mathrm{~L}^{-1}$ $\mathrm{KOH}$ electrolyte solution by using a Chenhua electrochemical workstation (CHI760E, China).

Using $N$-methyl pyrrolidinone (NMP) as a solvent, the $\mathrm{Ni@NiO@C} \mathrm{nanocomposites} \mathrm{were} \mathrm{mixed} \mathrm{with} \mathrm{both} \mathrm{super}$ carbon black and a polymer binder made of polyvinylidene fluoride (PVDF) with a weight ratio of 80:10:10, resulting in a black slurry. The electrode was prepared by coating the slurry onto copper foil and dried at $80^{\circ} \mathrm{C}$ for $12 \mathrm{~h}$ in a vacuum oven. The electrolyte solution was $1 \mathrm{~mol} \mathrm{~L}^{-1} \mathrm{LiPF}_{6}$ in a mixture of ethylene carbonate and diethyl carbonate with a volume ratio of $1: 1$ and a polyethene separator (Celgard 2400) was used as the separator. The lithium foil was used as the cathode of the 
coin cell. 2032-type coin cells were assembled in an Arfilled glove box (Mikrouna, super 1220/750/900), with both moisture and oxygen concentrations below $0.01 \mathrm{ppm}$. Cyclic voltammetry $(\mathrm{CV})$ and galvanostatic charge/discharge measurements were performed on a Chenhua electrochemical workstation (CHI660E, China) and a LAND galvanostatic charge-discharge instrument (CT2001A, China).

\section{RESULTS AND DISCUSSION}

The morphology of $\mathrm{Ni@NiO@C} \mathrm{nanocomposites} \mathrm{was}$ characterized using SEM and TEM, as shown in Fig. 2a-c. The Ni@NiO@C nanocrystals show a very uniform spherical shape with a diameter of 50-100 nm. Although they are overlapping, the $\mathrm{Ni@NiO@C} \mathrm{nanocomposites} \mathrm{are}$ separated by the $\mathrm{C}$ shell without agglomeration. In Fig. 2c, the Ni@NiO@C nanocomposites'core-shell structure can be clearly seen from the high-magnification TEM image. The dark-colored core is $\mathrm{Ni@NiO}$, and the $\mathrm{C}$ shell is flocculent and almost transparent. As shown in the highresolution TEM image (Fig. 2d), the interplanar spacing is measured to be $0.20 \mathrm{~nm}$, which corresponds to the (111) crystal plane of face center cubic structure $\mathrm{Ni}$. The $\mathrm{NiO}$ shell is confirmed by the X-ray diffraction (XRD) pattern shown in Fig. 3a. The diffraction peaks of $\mathrm{NiO}$ located at $37.2^{\circ}, 43.3^{\circ}$, and $62.8^{\circ}$ are detected, and correspond to the (311), (331), and (440) crystal planes of $\mathrm{NiO}$, respectively. Lastly, the $\mathrm{C}$ component is verified by the Raman spectrum of Ni@NiO@C nanocomposite. There are two

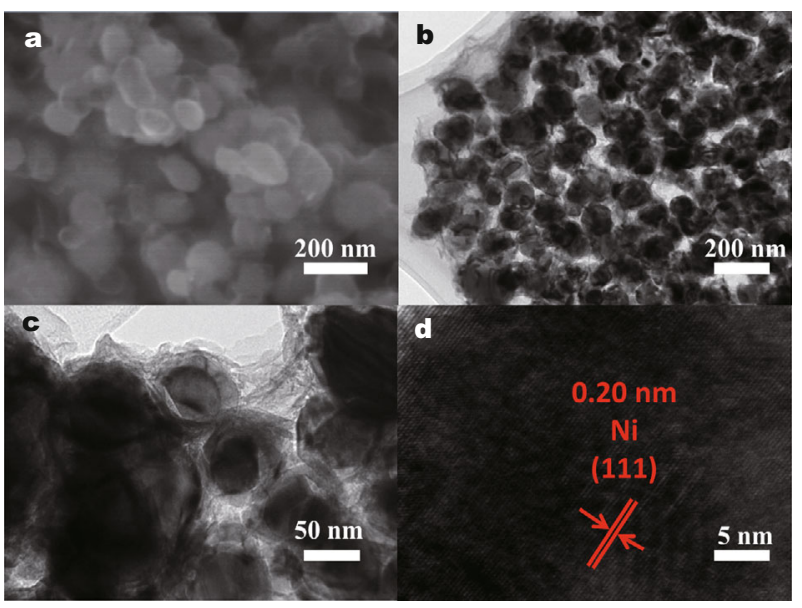

Figure 2 (a) SEM image, (b) low- and (c) high-magnification TEM images, and (d) HRTEM image of the Ni@NiO@C nanocomposites.

characteristic peaks for the carbon-based material in Fig. 3b: the D band for "disorder" and the G band for "graphite carbon", which are centered at 1340 and $1596 \mathrm{~cm}^{-1}$, respectively. The $\mathrm{N}_{2}$ adsorption-desorption isotherm of Ni@NiO@C nanocomposites is shown in Fig. 3c. The Barret-Joyner-Halenda (BJH) pore size distribution can be calculated from the adsorption branches (Fig. 3d). The calculated specific surface area is $301 \mathrm{~m}^{2} \mathrm{~g}^{-1}$, and the pore size distribution shows a predominant peak at $1.36 \mathrm{~nm}$.

The ORR catalytic activity of Ni@NiO@C nanocomposites was investigated in $0.1 \mathrm{~mol} \mathrm{~L}^{-1} \mathrm{KOH}$ solution by the three-electrode test system. The CV curves of
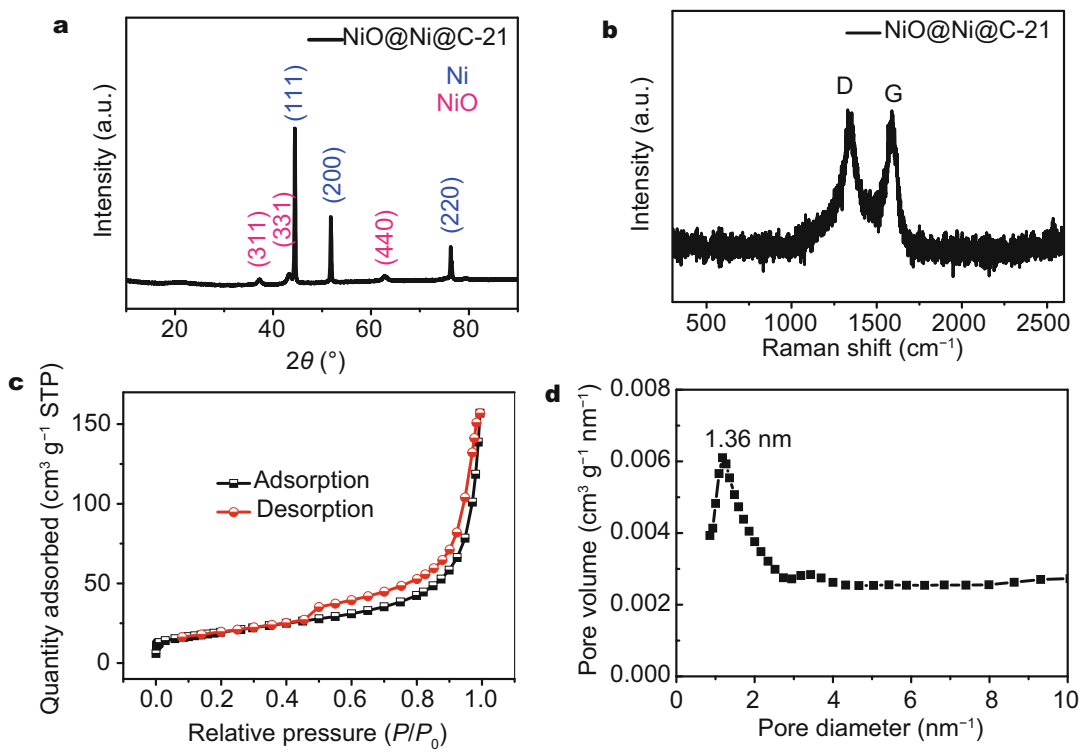

Figure 3 (a) XRD pattern, (b) Raman spectrum, (c) nitrogen adsorption-desorption isotherms, and (d) pore size distribution calculated from the adsorption isotherms of Ni@NiO@C nanocomposites. 

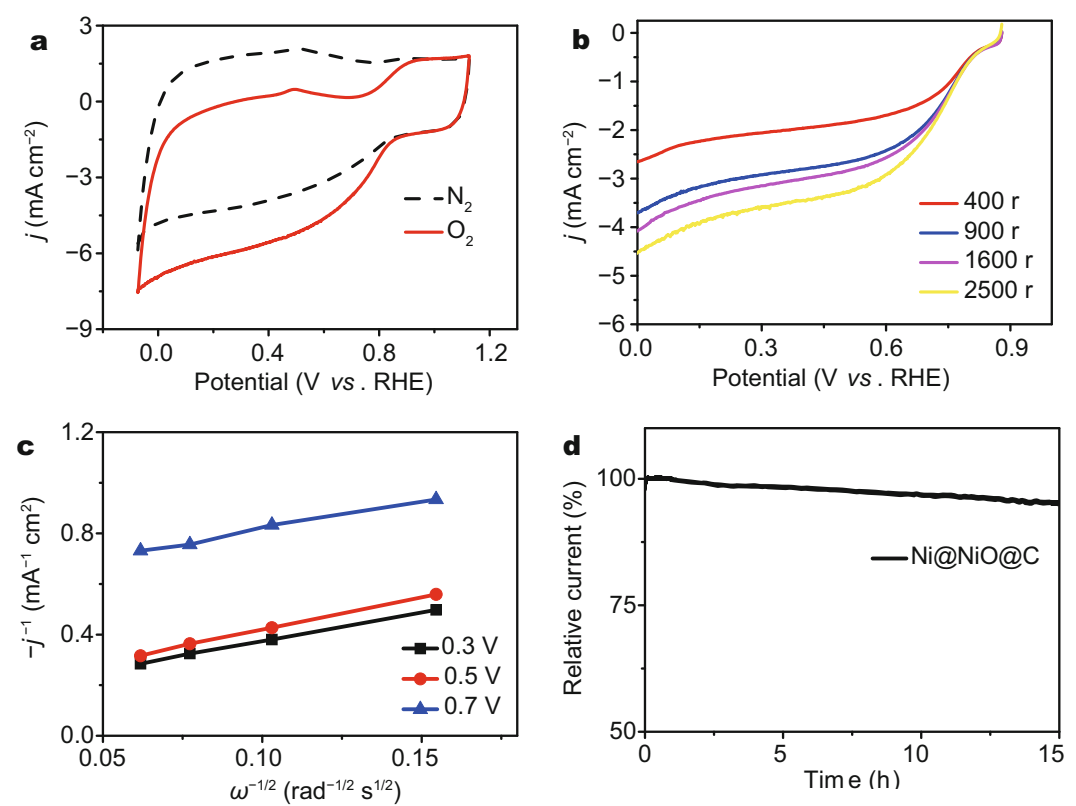

Figure 4 ORR catalytic activities of Ni@NiO@C. (a) CV curves of $\mathrm{Ni@NiO@C} \mathrm{in} \mathrm{N}_{2}$-saturated (black dashed line) and $\mathrm{O}_{2}$-saturated (red solid line) $1 \mathrm{~mol} \mathrm{~L}^{-1} \mathrm{KOH}$ at a scan rate of $50 \mathrm{mV} \mathrm{s}^{-1}$. (b) Polarization curves of $\mathrm{Ni@NiO@C} \mathrm{at} \mathrm{various} \mathrm{rotation} \mathrm{speeds} \mathrm{with} \mathrm{a} \mathrm{scan} \mathrm{rate} \mathrm{of} 5 \mathrm{mV} \mathrm{s}^{-1}$. (c) The corresponding KL plots at various potentials. (d) Current-time chronoamperometric response of Ni@NiO@C in $\mathrm{O}_{2}$-saturated 0.1 mol L ${ }^{-1} \mathrm{KOH}$ at $0.3 \mathrm{~V}$ with a rotation speed of $1600 \mathrm{rpm}$ for $15 \mathrm{~h}$.

Ni@NiO@C nanocomposites were acquired in $\mathrm{N}_{2}$-saturated and $\mathrm{O}_{2}$-saturated $0.1 \mathrm{~mol} \mathrm{~L}^{-1} \mathrm{KOH}$ with a scan range varying from -0.1 to $1.1 \mathrm{~V}$, as shown in Fig. $4 \mathrm{a}$. No discernible redox peaks were found in the CV of $\mathrm{Ni@-}$ NiO@C nanocomposites. However, the current density noticeably increased in $\mathrm{O}_{2}$-saturated electrolyte solutions compared to that in the $\mathrm{N}_{2}$-saturated electrolyte solutions at potentials below approximately $0.8 \mathrm{~V}$. In order to investigate the kinetics of ORR, polarization curves of the

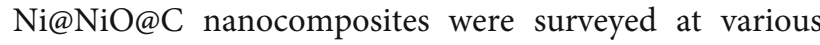
rotation speeds with a scan rate of $5 \mathrm{mV} \mathrm{s}^{-1}$ (shown in Fig. 4b). The limit current density increases with increasing rotation speeds (see Fig. $4 \mathrm{~b}$ ), which reveals the kinetics-limit behavior of ORR [20,21]. The diffusion layer of oxygen was thinner and more oxygen reacted on the electrode surface at high rotation speeds. The initial potential, half-wave potential, and ultimate diffusion current density are $0.87 \mathrm{~V}, 0.7 \mathrm{~V}$, and $4.6 \mathrm{~mA} \mathrm{~cm}^{-2}$, respectively, at a rotation speed of $2500 \mathrm{rpm}$. The corresponding Koutecky-Levich (KL) plots of Ni@NiO@C nanocomposites at various potentials are presented in Fig. 4c. The KL plots of Ni@NiO@C nanocomposites show strong linear relationships. The electron transfer numbers per $\mathrm{O}_{2}$ molecule are $3.95,3.49$, and 3.97 at $0.3,0.5,0.7 \mathrm{~V}$, respectively. These results indicate that the ORR of Ni@NiO@C nanocomposites follows a quasi-four-elec- tron pathway, which is similar to that of $\mathrm{Pt} / \mathrm{C}$ [22]. The stability of the Ni@NiO@C nanocomposite was evaluated by monitoring the current-time chronoamperometric response in $\mathrm{O}_{2}$-saturated $0.1 \mathrm{~mol} \mathrm{~L}^{-1} \mathrm{KOH}$ at $0.3 \mathrm{~V}$ with a rotation speed of $1600 \mathrm{rpm}$, which is shown in Fig. 4d. The current density can maintain $90 \%$ of its initial current density after $15 \mathrm{~h}$. These results indicate that the Ni@$\mathrm{NiO} @ \mathrm{C}$ nanocomposite is stable and can be used in methanol and alkaline fuel cells.

The LSV measurement results for the Ni@NiO@C nanocomposite electrocatalyst are shown in Fig. 5a. The highest activity overpotential is $380 \mathrm{mV}$ ( $v s$. reversible hydrogen electrode (RHE)) under the current density of $10 \mathrm{~mA} \mathrm{~cm}^{-2}$, which is comparable with those observed for bimetallic catalysts with excellent performances, such as $\mathrm{Ni}-\mathrm{Co}(\sim 390 \mathrm{mV})$ and $\mathrm{Mn}-\mathrm{Co}(410 \mathrm{mV})$ [23]. By comparison, a similar core-shell morphological structured Co@ $\mathrm{Co}_{3} \mathrm{O}_{4} @ \mathrm{C}$ synthesized by Martin group has an activity overpotential of $410 \mathrm{mV}$ at $10 \mathrm{~mA} \mathrm{~cm}^{-2}$ [24]. Moreover, the current density reached $114 \mathrm{~mA} \mathrm{~cm}^{-2}$ at a potential of $1.8 \mathrm{~V}$ ( $v s$. RHE). The kinetics and mechanism of the OER are usually studied in terms of the Tafel plot. In Fig. 5b, the Tafel slope of the Ni@NiO@C catalyst is calculated to be $55 \mathrm{mV} \mathrm{dec}^{-1}$ using a linear fit, which is much lower than those of Ni-Co $\left(\sim 73 \mathrm{mV} \mathrm{dec}^{-1}\right)$ and MnCo ( $\left.\sim 85 \mathrm{mV} \mathrm{dec}^{-1}\right)$ [23]. The result shows that the Ni@ 

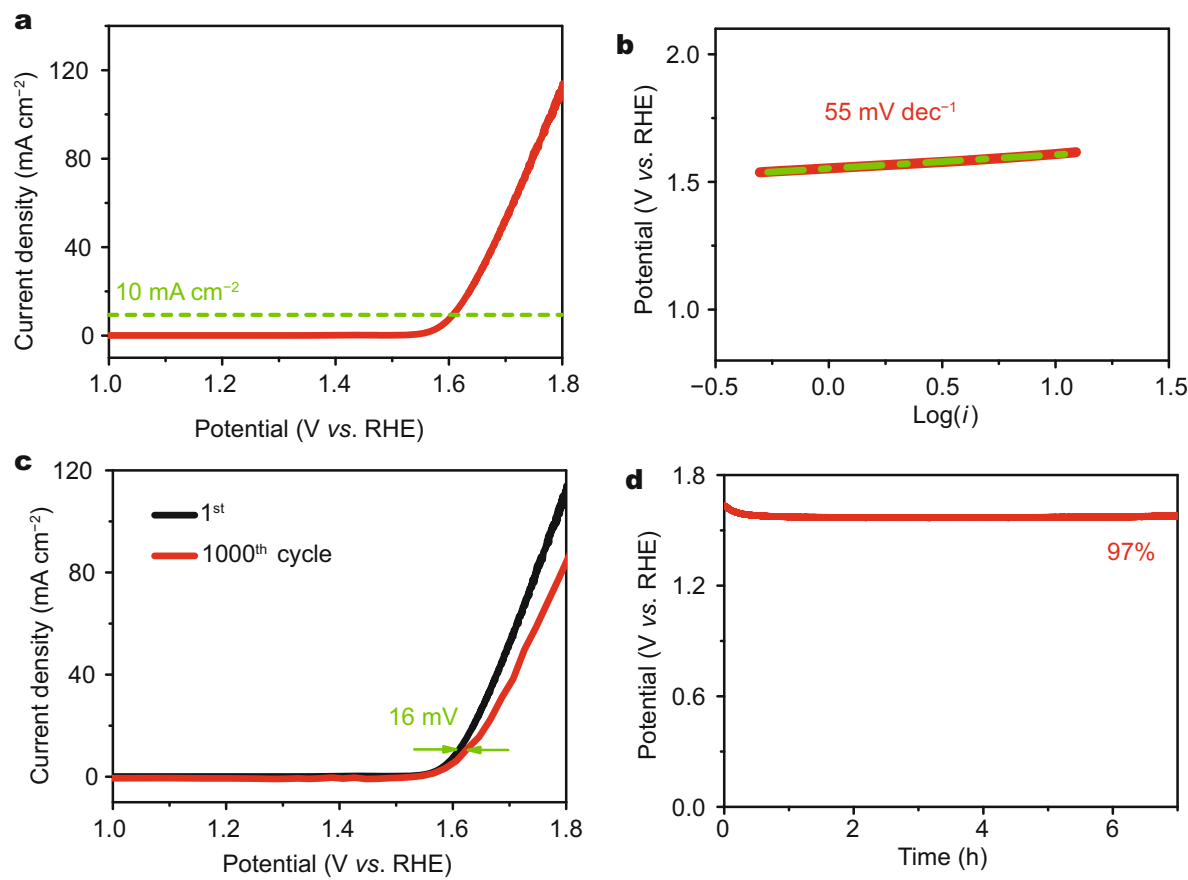

Figure 5 Electrocatalytic OER performances of Ni@NiO@C nanocomposites: (a) OER polarization curve, (b) calculated Tafel slope, (c) cycling durability test, and (d) the chronoamperometric response measured at a current density of $10 \mathrm{~mA} \mathrm{~cm} \mathrm{~cm}^{-2}$ over $7 \mathrm{~h}$
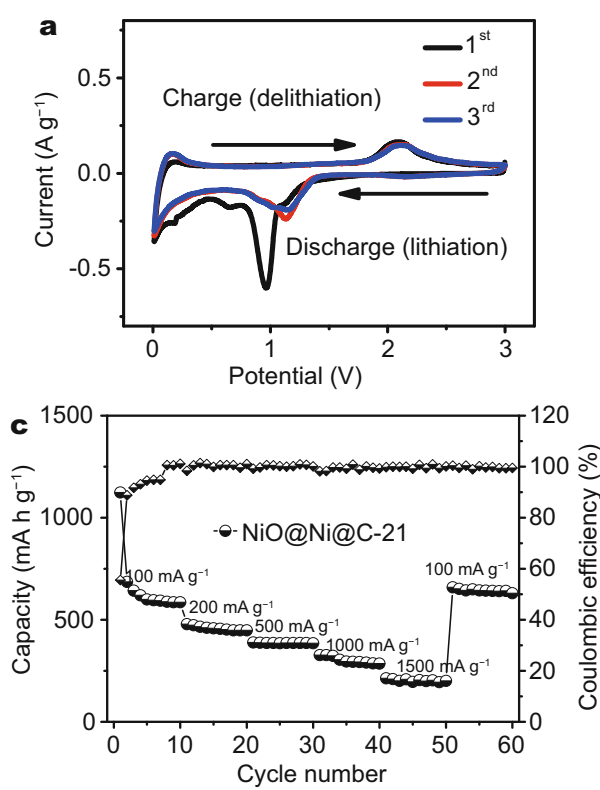
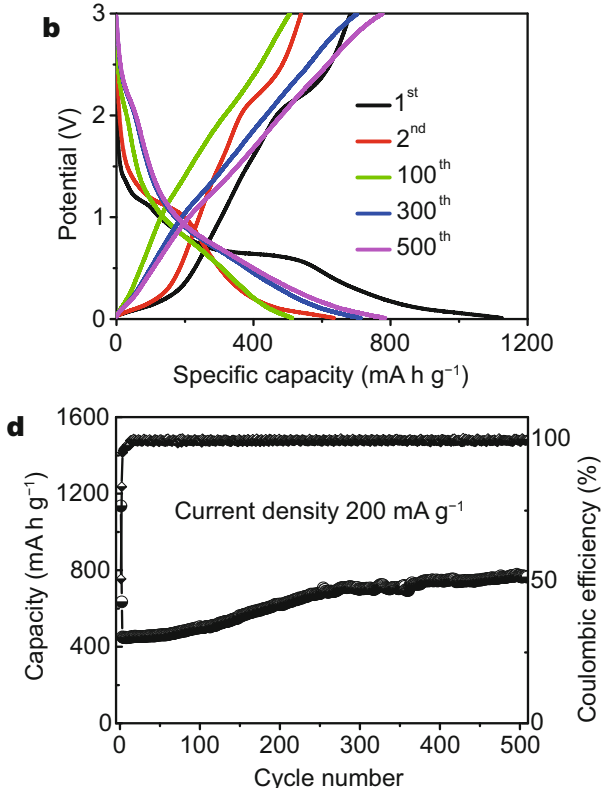

Figure 6 Electrochemical performances of the Ni@NiO@C nanocomposites for LIB applications: (a) CV curves, (b) galvanostatic discharge/charge voltage profiles at $200 \mathrm{~mA} \mathrm{~g}^{-1}$, (c) tests of rate performance at the increased rates from 100 to $1500 \mathrm{~mA} \mathrm{~g}^{-1}$, and (d) cycling performance at $200 \mathrm{~mA} \mathrm{~g}^{-1}$.

NiO@C nanocomposite catalyst is more efficient for the OER. Based on the LSV measurement, the CV results of the $1^{\text {st }}$ and $1000^{\text {th }}$ cycles are shown in Fig. 5c. After the $1000^{\text {th }}$ cycle, the Ni@NiO@C catalyst shows a slight loss of current density compared to the initial LSV. The difference in the activity overpotential is just $16 \mathrm{mV}$ under the 
current density of $10 \mathrm{~mA} \mathrm{~cm}{ }^{-2}$, suggesting that the Ni@$\mathrm{NiO} @ \mathrm{C}$ architecture is highly stable over long-term OER processes [25]. Furthermore, the chronopotentiometric response curve under a current density of $10 \mathrm{~mA} \mathrm{~cm}^{-2}$ exhibits a steady potential at $1.59 \mathrm{~V}$, as shown in Fig. $5 \mathrm{~d}$. The activity overpotential decreases by only $3 \%$ in a continuous experiment over $7 \mathrm{~h}$. All these excellent performances of the composites indicate that although physical factors like conductivity, structural defects, and increased surface area might influence the ORR and OER activities, the $\mathrm{C}$ component may have a role in improving the activity of nickel [26].

Electrochemical performances of the Ni@NiO@C nanocomposites for LIB applications [25] are shown in Fig. 6. In this experiment, Li foil is used as a cathode material and Ni@NiO@C is regarded as an anode material, and the load of Ni@NiO@C is approximately $1 \mathrm{mg}$. Three consecutive CV cycles are recorded in Fig. 6a. The $2^{\text {nd }}$ and $3^{\text {rd }}$ cycle $\mathrm{CV}$ curves show similar profiles at a scan rate of $0.1 \mathrm{mV} \mathrm{s}^{-1}$. In the first cathodic process, the initial reduction of $\mathrm{NiO}$ to $\mathrm{Ni}$ is induced by a conversion reaction $\left(\mathrm{NiO}+2 \mathrm{Li}+2 \mathrm{e}^{-} \rightarrow \mathrm{Ni}+\mathrm{Li}_{2} \mathrm{O}\right)$ [27]. Two small peaks can be observed at 0.43 and $0.83 \mathrm{~V}$, and preliminary decomposition of the electrolyte forms part of the reversible solid electrolyte interphase (SEI) layer [28]. Fig. 6b shows the galvanostatic discharge/charge performance measured at a current density of $200 \mathrm{~mA} \mathrm{~g}^{-1}$ between 0.01 and $3.0 \mathrm{~V}$ for the Ni@NiO@C nanocomposite [29]. The first discharge and charge capacities of 1125 and $683 \mathrm{~mA} \mathrm{~h} \mathrm{~g}^{-1}$, are much higher than those of commercial $\mathrm{NiO} 770$ and $380 \mathrm{~mA} \mathrm{~h} \mathrm{~g}^{-1}$, respectively, measured at a current density of $100 \mathrm{~mA} \mathrm{~g}^{-1}$ [30]. To further investigate the rate capacity, the Ni@NiO@C nanocomposite electrode was tested under various current densities between 100 and $1500 \mathrm{~mA} \mathrm{~g}^{-1}$, and the results are shown in Fig 6c. The capacities of the Ni@NiO@C nanocomposite decrease as the current rates increase. Importantly, after cycling at different rates, the capacity of the Ni@NiO@C nanocomposite can recover to the initial value. Fig. $6 \mathrm{~d}$ shows the cycling behaviors of the Ni@NiO@C nanocomposite at a rate of $200 \mathrm{~mA} \mathrm{~g}^{-1}$. After 400 laps, the capacity of the Ni@NiO@C nanocomposite stabilizes at $750 \mathrm{~mA} \mathrm{~h} \mathrm{~g}^{-1}$. A self-improving capacity during cycling has been found in Ni@NiO@C nanocomposites over 400 cycles, which is consistent with the observations in carbon-based anode materials [31,32]. This self-improvement ability can be attributed to the activating properties of the porous structure of the carbon layer [32]. The carbon layer can effectively decrease the charge transfer resistance and enhance the electron transfer at the interface between the electrode and electrolyte. Therefore, the Ni@NiO@C nanocomposite presents excellent electrochemical performance as an electrode in LIBs.

\section{CONCLUSIONS}

Multifunctional carbon-encapsulated Ni@NiO nanocomposites (Ni@NiO@C) were synthesized successfully. Morphological investigations suggested that the Ni@NiO@C nanocomposites were uniform and spherically shaped core-shell structures. The current density of the Ni@NiO@C nanocomposite for ORR can maintain 90\% of its initial value after $15 \mathrm{~h}$ in $\mathrm{O}_{2}$-saturated $0.1 \mathrm{~mol} \mathrm{~L}^{-1}$ $\mathrm{KOH}$ at $0.3 \mathrm{~V}$ with a rotation speed of $1600 \mathrm{rpm}$. From the LSV measurement, the highest activity overpotential of the Ni@NiO@C nanocomposite electrocatalyst was 380 $\mathrm{mV}$ (vs. RHE) under a current density of $10 \mathrm{~mA} \mathrm{~cm}^{-2}$; the current density reached $114 \mathrm{~mA} \mathrm{~cm}^{-2}$ at the overpotential potential of $1.8 \mathrm{~V}$ ( $v s$. RHE); and the Tafel slope was calculated using a linear fit as $55 \mathrm{mV} \mathrm{dec}^{-1}$. The CV results over 1000 cycles reveal that the Ni@NiO@C electrode possesses excellent electrochemical durability. Electrochemical performances of the Ni@NiO@C nanocomposite used as the LIB anode showed that the first discharge and charge capacities were 1125 and $683 \mathrm{~mA} \mathrm{~h} \mathrm{~g}^{-1}$, respectively, and the Coulombic efficiency reached about $64 \%$. After 400 laps, the capacity of the Ni@NiO@C nanocomposite stabilizes at $750 \mathrm{~mA} \mathrm{~h} \mathrm{~g}^{-1}$. The conduction enhancement in OER, reduction of the pulverization effect in LIB, and improved stability in ORR of the Ni@NiO@C nanocomposite were achieved, and these advancements led to exceptional performances in OER, LIB, and ORR.

Received 15 June 2017; accepted 7 August 2017; published online 6 September 2017

1 Wang H, Zhang X. Designing multi-shelled metal oxides: towards high energy-density lithium-ion batteries. Sci China Mater, 2016, 59: 521-522

2 Gao MR, Xu YF, Jiang J, et al. Nanostructured metal chalcogenides: synthesis, modification, and applications in energy conversion and storage devices. Chem Soc Rev, 2013, 42: 2986-3017

3 Lewandowicz G, Jankowski T, Fornal J. Effect of microwave radiation on physico-chemical properties and structure of cereal starches. Carbohydrate Polymers, 2000, 42: 193-199

4 Zhang G, Xu Y, Wang L, et al. Rational design of graphene oxide and its hollow $\mathrm{CoO}$ composite for superior oxygen reduction reaction. Sci China Mater, 2015, 58: 534-542

5 Zhao R, Xia W, Lin C, et al. A pore-expansion strategy to synthesize hierarchically porous carbon derived from metal-organic framework for enhanced oxygen reduction. Carbon, 2017, 114: 284-290

6 Liu M, Steven Tay NH, Bell S, et al. Review on concentrating solar 
power plants and new developments in high temperature thermal energy storage technologies. Renew Sustain Energ Rev, 2016, 53: 1411-1432

7 Xu D, Mu C, Xiang J, et al. Carbon-encapsulated $\mathrm{Co}_{3} \mathrm{O}_{4} @ \mathrm{CoO} @ \mathrm{Co}$ nanocomposites for multifunctional applications in enhanced long-life lithium storage, supercapacitor and oxygen evolution reaction. Electrochim Acta, 2016, 220: 322-330

8 Zhang X, Xiang J, $\mathrm{Mu} \mathrm{C}$, et al. $\mathrm{SnS}_{2}$ nanoflakes anchored graphene obtained by liquid phase exfoliation and $\mathrm{MoS}_{2}$ nanosheet composites as lithium and sodium battery anodes. Electrochim Acta, 2017, 227: 203-209

9 Liang C, Li Z, Dai S. Mesoporous carbon materials: synthesis and modification. Angew Chem Int Ed, 2008, 47: 3696-3717

10 Frackowiak E, Béguin F. Carbon materials for the electrochemical storage of energy in capacitors. Carbon, 2001, 39: 937-950

11 Balandin AA. Thermal properties of graphene and nanostructured carbon materials. Nat Mater, 2011, 10: 569-581

12 Zhang $\mathrm{T}$, He C, Sun F, et al. $\mathrm{Co}_{3} \mathrm{O}_{4}$ nanoparticles anchored on nitrogen-doped reduced graphene oxide as a multifunctional catalyst for $\mathrm{H}_{2} \mathrm{O}_{2}$ reduction, oxygen reduction and evolution reaction. Sci Rep, 2017, 7: 43638

13 Jović BM, Lačnjevac U, Jović VD, et al. Ni-(Ebonex-supported Ir) composite coatings as electrocatalysts for alkaline water electrolysis. Part II: Oxygen evolution. Int J Hydrogen Energ, 2016, 41: 20502-20514

14 Li H, Wang Y, Na H, et al. Rechargeable Ni-Li battery integrated aqueous/nonaqueous system. J Am Chem Soc, 2009, 131: 1509815099

15 Stacy J, Regmi YN, Leonard B, et al. The recent progress and future of oxygen reduction reaction catalysis: a review. Renew Sustain Energ Rev, 2017, 69: 401-414

16 Konopka A, Oliver L, Jr. RFT. The use of carbon substrate utilization patterns in environmental and ecological microbiology. Microbial Ecology, 1998, 35: 103-115

17 Faunce TA, Lubitz W, Rutherford AWB, et al. Energy and environment policy case for a global project on artificial photosynthesis. Energ Environ Sci, 2013, 6: 695-698

18 Wang X, Li X, Sun X, et al. Nanostructured NiO electrode for high rate Li-ion batteries. J Mater Chem, 2011, 21: 3571-3573

19 Lu Q, Lattanzi MW, Chen Y, et al. Supercapacitor electrodes with high-energy and power densities prepared from monolithic NiO/ Ni nanocomposites. Angew Chem Int Ed, 2011, 50: 6847-6850

20 Dong Y, Liu M, Liu Y, et al. Molybdenum-doped mesoporous carbon/graphene composites as efficient electrocatalysts for the oxygen reduction reaction. J Mater Chem A, 2015, 3: 19969-19973

21 Yang H, Liu J, Wang J, et al. Electrocatalytically active graphene supported MMo carbides $(\mathrm{M}=\mathrm{Ni}, \mathrm{Co})$ for oxygen reduction reaction. Electrochim Acta, 2016, 216: 246-252

22 Zheng Y, Jiao Y, Ge L, et al. Two-step boron and nitrogen doping in graphene for enhanced synergistic catalysis. Angew Chem Int Ed, 2013, 52: 3110-3116

23 Song W, Ren Z, Chen SY, et al. Ni- and Mn-promoted mesoporous $\mathrm{Co}_{3} \mathrm{O}_{4}$ : a stable bifunctional catalyst with surface-structure-de- pendent activity for oxygen reduction reaction and oxygen evolution reaction. ACS Appl Mater Interfaces, 2016, 8: 20802-20813

24 Aijaz A, Masa J, Rösler C, et al. Co@ $\mathrm{Co}_{3} \mathrm{O}_{4}$ encapsulated in carbon nanotube-grafted nitrogen-doped carbon polyhedra as an advanced bifunctional oxygen electrode. Angew Chem Int Ed, 2016, 55: 4087-4091

25 Pérez-Alonso FJ, Adán C, Rojas $\mathrm{S}$, et al. Ni/Fe electrodes prepared by electrodeposition method over different substrates for oxygen evolution reaction in alkaline medium. Int J Hydrogen Energ, 2014, 39: 5204-5212

26 Masa J, Weide P, Peeters D, et al. Amorphous cobalt boride $\left(\mathrm{Co}_{2} \mathrm{~B}\right)$ as a highly efficient nonprecious catalyst for electrochemical water splitting: oxygen and hydrogen evolution. Adv Energ Mater, 2016, 6: 1502313

27 Li X, Dhanabalan A, Bechtold K, et al. Binder-free porous coreshell structured $\mathrm{Ni} / \mathrm{NiO}$ configuration for application of high performance lithium ion batteries. Electrochem Commun, 2010, 12: $1222-1225$

28 Sun X, Si W, Liu X, et al. Multifunctional Ni/NiO hybrid nanomembranes as anode materials for high-rate Li-ion batteries. Nano Energ, 2014, 9: 168-175

29 Guo S, Liu W, Meng H, et al. Exchange bias and its training effect in $\mathrm{Ni} / \mathrm{NiO}$ nanocomposites. J Alloys Compd, 2010, 497: 10-13

30 Liang Z, Huo R, Yin YX, et al. Carbon-supported $\mathrm{Ni@NiO/} / \mathrm{Al}_{2} \mathrm{O}_{3}$ integrated nanocomposite derived from layered double hydroxide precursor as cycling-stable anode materials for lithium-ion batteries. Electrochim Acta, 2013, 108: 429-434

31 Arico E, Tabuti F, Fonseca FC, et al. Carbothermal reduction of the YSZ-NiO solid oxide fuel cell anode precursor by carbon-based materials. J Therm Anal Calorim, 2009, 97: 157-161

32 Lv W, Xiang J, Wen F, et al. Chemical vapor synthesized $\mathrm{WS}_{2}$ embedded polystyrene-derived porous carbon as superior longterm cycling life anode material for li-ion batteries. Electrochim Acta, 2015, 153: 49-54

Acknowledgements This work was supported by the National Natural Science Foundation of China (51571172, 51672240, 51571171, and 11404280), the Natural Science Foundation for Distinguished Young Scholars of Hebei Province (E2017203095), the Natural Science Foundation of Hebei Province (E2016203484 and A2015203337), and the Research Program of the College Science \& Technology of Hebei Province (ZD2017083 and QN2014047).

Author contributions $\mathrm{Xu} \mathrm{D}$ performed the experiments with help from Ruan $\mathrm{W}$ and $\mathrm{Du} \mathrm{X}$. Mu C wrote the manuscript with support from Wang B, Xiang J and Tian Y. Wen F and Liu Z conceived the research. All authors contributed to the general discussion.

Conflict of interest The authors declare that they have no conflict of interest.

Supplementary information online version of the paper.
Supporting data are available in the 


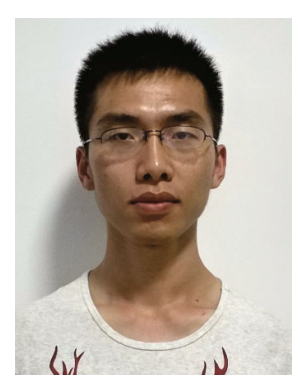

Dongyang Xu was born in 1991. He received his Master's degree in material physics from Yanshan University in 2017. His research interest focuses on the synthesis and application of porous carbon parcel metal and its oxide materials for the energy storage and electrochemical catalysis.

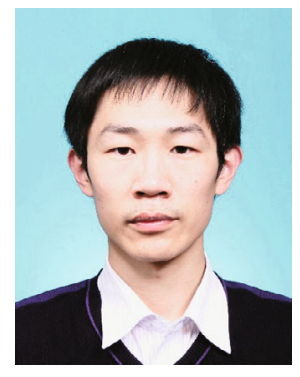

Congpu Mu was born in 1984 and joined Yanshan University in 2013. He completed his PhD in physics at Lanzhou University in 2013. His research is related to magnetic nanomaterials, from magnetic metals to magnetic oxide with their applications in microwave absorption and energy storage.

\section{多功能碳包覆的 $\mathrm{Ni@NiO}$ 纳米复合材料用于析氧反应、氧还原反应和锂离子电池电极的研究}

徐冬阳 ${ }^{1}$, 牟从普 ${ }^{2 *}$, 王博羽 ${ }^{2}$, 向建勇 ${ }^{1}$, 阮文君 ${ }^{1}$, 温福㫒 ${ }^{1^{*}}$, 杜夏 $^{1}$, 柳忠元 ${ }^{1^{*}}$, 田永君 $^{1}$

摘要 本文成功合成了多功能的碳包覆 $\mathrm{Ni} @ \mathrm{NiO}$ 纳米复合材料, 并将其用作析氧反应和氧还原反应催化剂以及锂离子电池的负极材料. 扫 描电镜和透射电镜照片表明 $\mathrm{Ni} @ \mathrm{NiO} @ \mathrm{C}$ 纳米复合物具有均一的球形核壳结构. 将 $\mathrm{Ni} \mathrm{NiO} @ \mathrm{C}$ 纳米复合物用作氧还原反应的催化剂时, 在 浓度为 $0.1 \mathrm{~mol} \mathrm{~L}^{-1}$ 的氢氧化钾溶液中以 $1600 \mathrm{rpm}$ 转速下连续反应 15 小时后, 电流密度仍然可以保持在初始值的 $90 \%$ 以. 作为析氧反应的

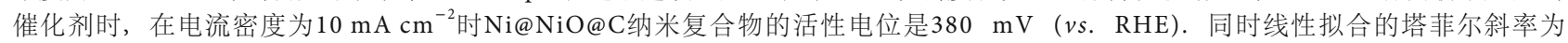
$55 \mathrm{mV} \mathrm{dec}{ }^{-1}$. Ni@NiO@C纳米复合物被用作锂离子电池的负极材料时, 在电流密度为 $200 \mathrm{~mA} \mathrm{~g}^{-1}$ 下循环 400 圈后, 电池容量还可以达到

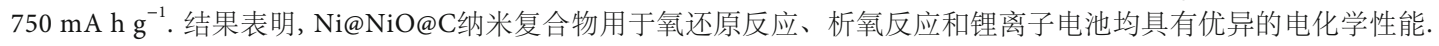

